\title{
O turismo nas Américas: territórios, experiências e novos desafios?
}

\section{Vincent Andreu-Boussut e Elodie Salin}

Tradutor: Lucilia Wuillaume

\section{CpenEdition Journals}

\section{Edição electrónica}

URL: https://journals.openedition.org/ideas/5691

DOI: 10.4000/ideas.5691

ISSN: 1950-5701

\section{Este artigo é uma tradução de:}

Le tourisme dans les Amériques : territoires, expériences et nouveaux enjeux ? - URL : https:// journals.openedition.org/ideas/4515 [fr]

Outra(s) tradução(ões) deste artigo:

Tourism in the Americas: Territories, Experiences and New Issues? - URL : https:// journals.openedition.org/ideas/4717 [en]

El turismo en las Américas: territorios, experiencias y ¿nuevos desafíos? - URL : https:// journals.openedition.org/ideas/5721 [es]

Editora

Institut des Amériques

Refêrencia eletrónica

Vincent Andreu-Boussut e Elodie Salin, «O turismo nas Américas: territórios, experiências e novos desafios?», IdeAs [Online], 12 | 2018, posto online no dia 16 novembro 2018, consultado o 18 outubro 2022. URL: http://journals.openedition.org/ideas/5691 ; DOI: https://doi.org/10.4000/ideas.5691

Este documento foi criado de forma automática no dia 18 outubro 2022.

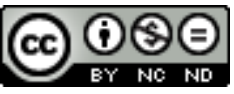

Creative Commons - Atribuição-NãoComercial-SemDerivações 4.0 Internacional - CC BY-NC-ND 4.0 https://creativecommons.org/licenses/by-nc-nd/4.0/ 


\title{
O turismo nas Américas: territórios, experiências e novos desafios?
}

\author{
Vincent Andreu-Boussut e Elodie Salin \\ Tradução : Lucilia Wuillaume
}

1 Ainda que o continente americano chegue somente em terceiro lugar no ranking mundial dos destinos do turismo internacional, após a Europa e a região Ásia-Pacífico, o fato turístico continua sendo importante, haja vista as 210,9 milhões de entradas internacionais em 2017, que representam $16 \%$ das entradas de turistas no mundo inteiro (OMT-UNWTO, 2018). Ainda mais importante é o fato de que alguns países dispõem também de um turismo interior altamente desenvolvido, como os Estados Unidos $^{1}$ e o Canadá. Esse mercado interno é, aliás, francamente predominante em alguns dos países mais desenvolvidos e em crescimento acelerado, como o Brasil. Dessa forma, esses fluxos turísticos, considerados em sua totalidade, estruturam fortemente as economias, as sociedades e os territórios americanos. No âmbito do conjunto das regiões americanas, por razões geo-históricas, culturais, econômicas e políticas, a turistificação dos territórios continua sendo um processo desigual e diferenciado. Assim, a América do Norte recebe a maior parte dos turistas internacionais, com 137 milhões de entradas em 2017, enquanto que, nesse mesmo ano, os números foram de, somente, 36,7 milhões na América do Sul, 26 milhões no Caribe e 11,2 milhões na América Central. Nessa geografia desequilibrada, os Estados Unidos aparecem como líder incontesto no plano, tanto do turismo doméstico, quanto do internacional, classificando-se frequentemente como o terceiro país mais visitado do mundo, como em 2017, com 76,9 milhões de visitantes internacionais (OMT-UNWTO, 2018), muito à frente do México (39,3 milhões) e do Canadá (20,8 milhões). Os mais importantes destinos do continente, Argentina, Brasil, Chile, e República Dominicana, vêm bem depois, com somente um pouco mais de 6 milhões de entradas de turistas internacionais. Ainda que essa situação resulte, em parte, de um desenvolvimento já antigo do turismo nos Estados Unidos ou no Canadá, desde 1850, e também na Argentina, ela reflete também e, principalmente, as disparidades do desenvolvimento econômico dos diferentes países e reproduz a hegemonia entre o Norte e o Sul, observável, geralmente, nas esferas econômicas e sociopolíticas. O turismo tem efeitos 
cumulativos notórios: além de serem mais turísticos, os países mais ricos também se beneficiam dos impactos econômicos que resultam dessa atividade. Devemos lembrar que os Estados Unidos, sozinho, acumula as maiores receitas turísticas do mundo, com 1035,7 bilhões de dólares gastos em 2017 em turismo internacional ${ }^{2}$ e doméstico (US Travel Association, 2018).

2 No entanto, essa geografia do turismo americano vem sido reconsiderada há, pelo menos vinte anos, pois alguns destinos das Américas, Central e do Sul, estão alcançando os norte-americanos, tendendo, com isso, a reduzir as diferenças territoriais. Desde 1995, o número de turistas internacionais aumentou mais de 330 \% na América Central e $213 \%$ na América do Sul, enquanto essa progressão foi de, somente, 86 \% no Caribe e $70 \%$ na América do Norte (OMT-UNWTO, 2018).

3 Desde a década de 1970, as pesquisas envolvendo o turismo tomaram de assalto os espaços americanos em várias disciplinas das ciências sociais (geografia, história, antropologia...) ajudando a expandir o campo dos tourism studies. Os trabalhos científicos norte-americanos sobre o turismo refletiram durante muito tempo a diversidade das dinâmicas dos territórios turísticos, em vez de alimentar as teorias do desenvolvimento do turismo (Mitchell L., 1984). O desenvolvimento do turismo nos espaços protegidos, a diversidade das formas de turismo rural sob o prisma de questões identitárias e fundiárias, o desenvolvimento urbano através de grandes estruturas turísticas, continuam a alimentar um sem número de pesquisas. Durante esse processo, a literatura científica também contribuiu para a gestão e o monitoramento dos territórios, produzindo conhecimento ou ferramentas de análise úteis para a decisão pública, principalmente no caso de gestão urbana ou dos parques nacionais. De forma mais ampla, muitos são também os trabalhos que abordam a história do turismo, haja vista o papel pioneiro desempenhado pelos Estados Unidos na invenção de modelos espaciais específicos (Andreu-Boussut V., 2012), amplamente divulgados no âmbito de uma cultura de massa do turismo (Maskintosh W., 2018). Mais recentemente, pesquisas anglófonas e hispanófonas trouxeram à tona uma visão política das consequências do fenômeno globalizado do turismo, mais especificamente na América Latina. Essa abordagem, defendida, principalmente, por etnólogos e geógrafos, mostrou os efeitos perversos do turismo, assimilado a uma extensão do colonialismo (Nash D., 1989; Mc Cannell D., 1976) ou analisado como uma realidade pós-colonial (Hall M. e H. Tucker, 2004; Martinez Mauri M., 2018). Essa denúncia crítica do turismo desloca-se, atualmente, para uma análise da dependência e insiste nas desigualdades entre Norte e Sul e nas desigualdades de classes no âmbito da globalização (Marie Dit Chirot C., 2018; De Cássia Ariza da Cruz, 2018). Após as grandes conferências das Nações Unidas sobre o desenvolvimento sustentável (a Eco-92, em 1992, os Objetivos do Milênio, em 2000), a pesquisa começou a se restruturar, no entanto, vinculando-se à gestão pública dos territórios, aos movimentos sociais e ao turismo comunitário. Dessa forma, no Brasil e em outros locais da América Latina, os estudos sobre o turismo tratam, com frequência, das articulações entre meio ambiente, espaços protegidos e inclusão social (Irving M., 2015). 


\section{Turismo, fator de recomposição dos territórios: da consolidação dos destinos, às novas frentes turísticas}

4 O turismo é, antes de tudo, um potente fator de transformação dos territórios. Ele determina a produção histórica e contemporânea de estruturas especializadas em todo o continente americano, o que explica a diferenciação e a diversificação de toda uma tipologia de espaços turísticos. Nesse processo, três dimensões merecem uma atenção especial: as condições de turistificação dos territórios, o processo de desenvolvimento do turismo no longo prazo e as consequências territoriais do desenvolvimento turístico.

Questionar-se sobre os fatores que explicam a turistificação, consiste em esclarecer e desconstruir o que alguns geógrafos franceses chamam de "moment de lieux", (Equipe MIT, 2005). O surgimento de novos locais no planisfério dos destinos turísticos explicase, de forma geral, pela evolução das representações culturais, a invenção e o sucesso de práticas turísticas e pelo aumento do poder aquisitivo. No Brasil, Hervé Théry demonstra, assim, o papel desempenhado pelo crescimento da classe média, a partir do governo Lula, na estruturação de um setor turístico forte, onde o turismo doméstico é fortemente preponderante em relação ao turismo internacional. A consolidação dos dois destinos mais importantes, Nordeste e região de São Paulo, explica-se, assim, pela proximidade das bacias emissoras de turistas, cujos recursos financeiros melhoraram, e pela construção de um "desejo" de férias. Bem menos mobilizada, a mudança climática foi também o ponto de partida da estruturação de novos destinos nos territórios, cuja descompartimentação alimenta a implementação de frentes pioneiras do turismo. Para Alain Grenier, o aquecimento global e o degelo do Ártico canadense vêm favorecendo, há aproximadamente vinte anos, o surgimento de um turismo de cruzeiros polares para turistas abastados, nos quais o imaginário da fronteira inaccessível foi reaceso. A evolução desse turismo de aventuras insere-se em um paradoxo: por um lado, o surgimento de novas rotas marítimas mundiais perturba a geopolítica global, por outro, a abertura econômica do território inuíte renova as necessidades de proteção dos patrimônios e de participação dessas populações. Quanto ao papel das representações na turistificação dos territórios, Serge Jaumain dissecou a produção dos guias turísticos impressos desde a década de 1960, no que diz respeito à apresentação da história do Quebec. O guia desempenha o papel de revelador da evolução das representações de um território e de reflexo de suas transformações socioculturais e políticas. Os guias turísticos anglófonos e francófonos do Quebec são testemunhas da revalorização progressiva das populações autóctones e a politização acentuada da representação da história nacional.

6 Posteriormente, o desenvolvimento do turismo no longo prazo poderá ser analisado nos planos geopolítico e econômico, pois os grandes destinos se transformam, de forma geral, ao sabor de uma concorrência altamente globalizada dos mercados turísticos e do plano dos modelos territoriais em curso. Assim, o geógrafo Richard W. Butler conceitualizou um modelo de crescimento ou de declínio dos destinos de acordo com um ciclo de vida determinado, o Tourism Area Life Cycle (TALC), cuja celebridade científica está fortemente ligada à sua utilização para a compreensão do desenvolvimento de muitos espaços americanos, sejam eles parques nacionais, espaços urbanos ou estações balneárias (Butler R., 2006a, 2006b). Dessa forma, Michel Desse, Jusline Rodné, Monique Gherardi e Simon Charrier demonstram que o desenvolvimento turístico das ilhas do Caribe, impulsionado, principalmente, pelos 
cruzeiros (Dehoorne O., 2007; Dehoorne O. e N. Petit-Charles, 2011), é explicado, tanto pela conjuntura econômica mundial, quanto pela forma pela qual os agentes públicos e privados locais se engajam no processo de desenvolvimento. Dois modelos de desenvolvimento se enfrentam: um segregativo e fechado, cuja genealogia é a da resort community, e um outro de desenvolvimento integrado aos espaços de vida dos habitantes.

7 Finalmente, os efeitos do desenvolvimento turístico sobre os territórios e suas sociedades tornaram-se uma temática clássica dos estudos sobre o turismo, principalmente, na América Latina (Wilson T., 2008). Sobre isso, mediante uma análise pormenorizada da turistificação de territórios produtores de cacau na República Dominicana e no Costa Rica, Laura Henry explora a valorização, pelo turismo, desse tipo de produção agrícola. Longe dos imaginários do turismo balneário dominicano e do turismo de natureza costa-riquenho, o desenvolvimento do turismo rural serve, ao mesmo tempo, de vitrine para o cacau de qualidade, favorecendo, ao mesmo tempo, o empoderamento das mulheres. De forma mais ampla, é claro que as ciências sociais revelam com frequência o poder subversivo do turismo para as sociedades, mas, ao mesmo tempo, demonstram também seu poder de transformação, questionando as dinâmicas territoriais sob o prisma da sustentabilidade.

\section{Experiências para repensar o equilíbrio entre turismo, sociedades e meio ambiente: a sustentabilidade em questão(ões)}

8 Na literatura científica e técnica, o território americano é frequentemente mobilizado por suas experiências de desenvolvimento sustentável no turismo local, inspirado pelo guia de boas práticas publicado recentemente pela Organização Mundial do Turismo e pela Organização dos Estados Americanos. (UNWTO et Organization of American States, 2018). É preciso dizer que, há muito tempo, nos Estados Unidos, há questionamentos sobre a busca de um melhor equilíbrio entre o desenvolvimento turístico e a proteção do ambiente natural. Com efeito, a invenção e a implementação dos primeiros parques naturais, já em 1870, inicialmente nos Estados Unidos e, em seguida, no Canadá, foram acompanhadas, concomitantemente, da turistificação desses locais. (Butler R. et S. Boyd, 2000; Depraz S. e S. Héritier, 2012). Na década de 1930, o rápido crescimento do público de visitantes citadinos e de adeptos de acampamentos, buscando conectar-se com a natureza, teve grande impacto nos ecossistemas protegidos. Terence Young resgata, assim o papel pioneiro que desempenha Emilio P. Meinecke na invenção das primeiras medidas de gestão desses impactos ecológicos e na formalização de um verdadeiro modelo de gestão dos fluxos de visitantes nos espaços naturais (zoneamento dos usos, canalização do público, regras específicas para adaptação dos acampamentos...) que foi amplamente exportado, a partir dessa época, para fora dos Estados Unidos. O Campground Policy publicado em 1932 continua, aliás, sendo a referência em termos de adaptação de acampamentos com acesso por automóvel nos parques nacionais. $O$ design concebido por Meinecke permite, ao mesmo tempo, reduzir a pegada ecológica dos usuários e reforçar sua imersão na natureza. Desde essa época, vários espaços protegidos americanos tornaram-se famosos destinos turísticos, para os quais o equilíbrio entre a proteção dos meios naturais e a manutenção, ou até o aumento da frequência, continua sendo essencial. A escolha dos meios de gestão mais 
adaptados faz, muitas vezes, objeto de uma governança local. No Parque Nacional da Guadeloupe, Vincent Andreu-Boussut, Caroline Rufin-Soler e Céline Chadenas mostram que a implementação dessa governança esbarra em visões divergentes dos agentes socioeconômicos locais, no que diz respeito ao grau de abertura ao turismo e a intensidade dos usos, apesar da existência de uma consciência patrimonial relativamente compartilhada. Os espaços protegidos terrestres já dispõem, hoje em dia, de ferramentas comprovadas em matéria de gestão do turismo, no entanto, a área marinha apresenta um território novo, onde as experiências de turismo sustentável e gestão dos usos turísticos, ainda são recentes (zoneamento dos usos, código de boas práticas...).

9 Fora dos espaços protegidos, locais de experiência privilegiados, o desenvolvimento balneário de massa, iniciado no México e no Caribe a partir da década de 1970 (Weaver D., 1990; Hiernaux D., 2007; Dehoorne O. e al., 2010), foi imediatamente criticado por seus impactos ambientais e parcos resultados econômicos para as populações locais (Weaver D., 2001; Hiernaux-Nicolas D., 2008). Nesse contexto, foram criadas práticas turísticas alternativas (Weaver D., 2001), como a do arquiteto mexicano Héctor Ceballos-Lascurain que apresentou a primeira definição de ecoturismo, em 1983 (Ballantyne R. et J. Packer, 2013). O modelo ecoturístico, cujos resultados econômicos financiam projetos de proteção dos ambientes naturais criados pelas comunidades locais, tem notável sucesso (Ceballos-Lascurain $\mathrm{H}$. , 1987) nas ilhas caribenhas (Douglas J., 1992; Weaver D., 1993) e na América Latina. Finalmente, em todo o continente americano, alguns agentes locais experimentam capacidades turísticas, demonstrando, assim, que a economia do turismo está longe de concentrar-se somente nas mãos de grandes grupos nacionais ou internacionais. No Quebec, Sylvain Salaméro, Gilles Caire e Christiane Gagnon demonstram que, nos territórios em dificuldade demográfica e econômica, os agentes socioeconômicos do turismo (comunidades autóctones, pequenas empresas...) mobilizam-se em cooperativas de solidariedade onde a governança em diversas frentes é um princípio central de gestão das atividades turísticas e onde a distribuição dos resultados econômicos alimenta a dinâmica local do emprego. A vitalidade do turismo cooperativo do Quebec não deve, no entanto, esconder sua dificuldade em gerar impactos econômicos suficientes para eliminar as dinâmicas regionais que tendem ao declínio.

Se é verdade que a mudança climática ameaça, atualmente, a sustentabilidade dos territórios turísticos, ela oferece, também, todo um horizonte de oportunidades e os obriga a tentar novas experiências e fazer inovações. Para Vincent Andreu-Boussut, Caroline Rufin-Soler e Céline Chadenas, o desaparecimento programado das ilhotas do Grand Cul-de-Sac Marin nas ilhas da Guadalupe, fez com que o parque nacional organizasse, em parceria com os agentes econômicos, uma reflexão coletiva sobre o futuro dos usos turísticos. Nos Estados Unidos, Matthew McCourt e Gabriel Perkins mostram que, ainda que a mudança climática ameace o turismo invernal, ela também é uma excelente oportunidade para incitar a união da sociedade civil. Um bom exemplo são os projetos skiable village com maior sustentabilidade territorial. Foi assim que, em Bethel, no Maine, uma comunidade de voluntários, tomou sob sua responsabilidade a organização de uma competição de esqui nórdico, evitando seu cancelamento por razões climáticas. O nome do evento foi mudado para Protect our Winters e ele passou a ter o objetivo de atenuar a mudança climática, limitando os deslocamentos em automóvel dos participantes durante a competição. Ainda que a redução das emissões 
de $\mathrm{CO}_{2}$ fosse pequena, considerando as emissões totais produzidas pelos participantes em seus deslocamentos turísticos, numerosos foram os benefícios locais dessa experiência e do trabalho voluntário para o território. Mais renda foi gerada com gastos efetuados pelos visitantes e a capacidade da sociedade local em construir um projeto compartilhado de desenvolvimento turístico pertinente que levasse em conta as questões do meio ambiente global ficou evidenciada.

\section{A importância da questão comunitária para o desenvolvimento do turismo}

11 Ainda que seja percebido como motor de desenvolvimento econômico e social, o turismo comunitário, corresponde a uma concepção que evoluiu a partir do fim dos anos 1990, denominada de Turismo Pró-Pobre (Figueroa Pinedo J. et al., 2014). Gerando acessibilidade, oportunidades e emprego em regiões isoladas e carentes, o turismo comunitário pode também provocar uma conscientização em torno da diversidade cultural e a proteção, seguida de valorização, dos patrimônios, naturais, culturais e imateriais. As populações autóctones do Iucatã contribuem, com efeito, para o desenvolvimento local de sua comunidade restaurando seu patrimônio natural e participando da implantação de um programa nacional de turismo alternativo em área indígena. Desconstruindo uma iniciativa de turismo comunitário, Samuel Jouault enfatiza o surgimento de locais pioneiros que propõe uma alternativa às práticas turísticas em uma região marcada pelo turismo de massa (Riviera Maya). A turistificação do interior do território maia, tomando como exemplo um vilarejo yokdzonot, ilustra a transformação e a inversão das hierarquias espaciais e sociais. Durante muito tempo, o cenote (gruta inundada que forma um poço a céu aberto) foi percebido como um local marginalizado, sendo até utilizado como aterro a céu aberto. Agora, no entanto, foi transformado em local com grande atratividade, adaptado ao mergulho, e administrado de forma comunitária.

Apesar dos vários exemplos virtuosos, foram levantadas críticas ao Turismo Pró-Pobre (Harrison D., 2008), denunciando sua incapacidade em reduzir a pobreza ou problemas sociais e ambientais nas comunidades locais. O Exemplo dos índios Gunas no Panamá, mostra que, ainda que seja autogerenciado com competência, o turismo autóctone não é, necessariamente, sustentável. A entrevista realizada por Johanna Durget e Elodie Salin com Iniquipili Chiari expõe uma face pouco animadora do turismo comunitário na região litoral autônoma de Guna Yala. O modelo turístico, exclusivamente administrado pelos Gunas, propõe atividades balneárias em várias ilhas do arquipélago. Esse modelo, que é diferente do ecoturismo, propõe uma gestão comunitária bastante hierarquizada que parece favorecer a abordagem não sustentável de uma atividade turística bastante lucrativa e que gera conflitos sociais e ambientais, tanto na sociedade Guna, quanto no governo panamenho.

13 Então, de que forma o ecoturismo pode representar uma oportunidade para as populações autóctones e uma opção de destino turístico? Na floresta amazônica brasileira, Bastien Beaufort interessou-se pelo projeto ecoturístico Vinte Quilos concebido pelos índios Sateré Mawé em torno de um recurso agrícola e patrimonial, o guaraná, e centrado no conceito de etno desenvolvimento. Essa oportunidade de turismo comunitário é sustentado pelo projeto de comércio justo implementado desde 1994. Os resultados da turistificação são ainda balbuciantes, no entanto, as perspectivas 
de implementação parcial e tímida na Amazônia brasileira parecem fazer surgir uma possível frente pioneira turística. No surgimento desses novos destinos, Alain Grenier questiona-se, com clareza a propósito da participação das populações locais, pois na Antártica canadense, a turistificação dos territórios inuit tem sido feita, em grande parte, sem a participação das comunidades.

\section{Turistificação e patrimonializações: uma co- construção?}

14 O turismo está no âmago das questões ligadas à conservação e ao desenvolvimento dos bens patrimoniais, como uma ferramenta de validação das estratégias de desenvolvimento trazidas pela concessão de selos, ou como um objeto a ser gerenciado e controlado (Bourdeau L., M. Gravari-Barbas e al., 2012, Gravari Barbas M., S. Jacquot, 2014). A vontade de alcançar o reconhecimento internacional e a longa elaboração dos dossiês de candidatura da Unesco fazem com que o local e o global dialoguem, propulsando os espaços em vias de patrimonialização para a arena globalizada do turismo.

15 Para a Convenção do Patrimônio Mundial, o Valor Universal Excepcional (VUE) garante a unidade do conjunto de bens, enquanto enfatiza a diversidade dos destinos e de sua enunciação, orientando a renovação das abordagens, com o aparecimento em 1992 de novas categorias, como as paisagens culturais. Elodie Salin propõe uma análise comparada de três espaços certificados com o selo de paisagem cultural da Unesco, mediante a argumentação de seus valores universais excepcionais. Quer seja o café na Colômbia, o Agave (planta da Tequila) no México ou a Quebrada de Humahuaca na Argentina, os dossiês de candidatura das três paisagens culturais tentam construir um discurso, uma narrativa patrimonial, a serviço da turistificação dos territórios. A importância das imagens e dos discursos, algumas vezes, externos e ou veiculados por agentes específicos dos territórios, foi enfatizada aqui para mostrar o surgimento de uma identidade ou, até mesmo, de uma marca territorial forte, passando pela estetização das paisagens, ainda que, para isso, seja preciso construir uma imagem fictícia, afinada com a imagem que os visitantes têm do destino. Essas novas narrativas mudaram a significação do bem mediante a passagem do local ao global (DjamentTran G., E. Fagnoni, S. Jacquot, 2012).

16 A fábrica patrimonial, enquanto construção política, social e cultural se inscreve em um contexto de globalização em que as expectativas das comunidades locais podem entrar em conflito com a dos tomadores de decisão. Os conflitos de gestão dos destinos e as questões ligadas à apropriação, inclusive, no plano imaterial e simbólico, levantam questões de governança patrimonial e turística. O patrimônio pode, então, ser integrado às políticas turísticas, como uma vantagem comparativa que reforça a atratividade dos territórios. Elsa Broclain, Linda Boukhris, Sébastien Jacquot e Elodie Salin destacam o impacto internacional e a importância da prática do tango na cidade de Buenos Aires, que alimenta um imaginário fecundo e um marketing territorial a serviço da reancoragem do tango em seu berço original. A demonstração da instrumentalização do tango, declarado patrimônio cultural imaterial em 2009 pelas autoridades de Buenos Aires, foi seguida de múltiplas iniciativas privadas que criam uma verdadeira economia turística do tango. A tensão é, no entanto, forte entre um patrimônio imaterial globalizado e apresentado aos turistas nos tango-shows ou nos 
megaeventos e um tango mais social, identificado pelos portenhos do mundo tanguero como patrimônio local. A ideia de resistência a uma forma hegemônica de patrimonialização, que acompanha a turistificação dos destinos, foi retomada por Sébastien Jacquot que propõe o estudo da cidade de Valparaiso sob o prisma do surgimento controverso de um destino do turismo cultural. Para reverter a imagem de cidade em crise, o município apostou no turismo patrimonial, reforçado pela inscrição ao patrimônio mundial em 2003. As lógicas de proteção e concessão de selos, acompanhadas por grandes projetos urbanísticos, geram mutações urbanas, sociais e empresariais que transformam as paisagens urbanas. As controvérsias veiculadas pelos habitantes visam questionar os processos de gentrificação, de retirada das populações locais residentes, de especulação e turistificação excessiva dos cerros patrimonializados, levando à transformação de usos e apropriações dos bairros da Unesco. Uma dilatação das práticas turísticas também pode ser observada, para além das áreas mais emblemáticas, produzindo uma geografia turística alternativa e patrimonial da cidade.

\section{NOTAS}

1. Os Estados Unidos contabilizaram 2,25 bilhões de saídas individuais para estadia turística (visitas por pessoa) em 2017 (US Travel Association, 2018).

2. No plano do turismo internacional, os Estados Unidos têm $18 \%$ da fatia de mercado turístico global.

3. Momento de lugar, em tradução livre. Espaço de tempo mais ou menos preciso onde um local específico (ou uma área ou rede de locais), encarna uma situação de alcance geral, indo além das questões relativas ao local em si; logo, o momento onde o lugar, em decorrência da invenção ou da consolidação de uma prática, ou de forma mais geral, de uma inovação social com dimensão espacial confirmada, tornou-se uma referência, e até mesmo um modelo para outros locais: "Durée plus ou oins précise où un lieu donné (mais aussi une aire ou un réseau de lieux) incarne une situation de portée générale dépassant l'enjeu du lieu lui-même; donc le moment où le lieu, en raison de l'invention ou de la consolidation d'une pratique ou, plus généralement d'une innovation sociale à dimension spatiale affirmée, a constitué une référence, voire un modèle pour d'autres lieux." (http:// geoconfluences.ens-lyon.fr/glossaire/moment-de-lieu).

\section{AUTORES}

\section{VINCENT ANDREU-BOUSSUT}

Maître de conférences en géographie. UMR ESO 6590 CNRS, Le Mans Université. vincent.andreuboussut@univ-lemans.fr 


\section{ELODIE SALIN}

Maîtresse de Conférences en géographie, Le Mans Université, Laboratoire Espaces et Sociétés (UMR ESO 6590 CNRS), Chercheuse associée EIREST (Equipe interdisciplinaire de Recherche Sur le Tourisme) - Université Paris I Panthéon-Sorbonne 